At day 0 and appropriate time intervals until the final dose was dispensed and the lock-out mechanism of the inhaler was activated, the following parameters were assessed: water content, degradation products, content per cartridge, delivered dose (DD), fine particle dose (FPD) and microbial growth. All results, notably DD and FPD (Figure 1), were within the expected range and well inside the specifications applied during development. More precisely, the mean results of DD for aclidinium bromide were between $370 \mu \mathrm{g}$ and $451 \mu \mathrm{g}$ (specification 320-480 $\mu \mathrm{g}$ ) and for FPD between $139 \mu \mathrm{g}$ and $182 \mu \mathrm{g}$ (specification $\geq 80 \mu \mathrm{g}$ ), while the mean values of DD for formoterol fumarate dihydrate were between $10.1 \mu \mathrm{g}$ and $13.1 \mu \mathrm{g}$ (specification 9.6-14.4 $\mu \mathrm{g}$ ) and for FPD between $2.5 \mu \mathrm{g}$ and $3.7 \mu \mathrm{g}$ (specification $\geq 1.8 \mu \mathrm{g}$ ).

The studies show that stable pharmaceutical quality can be guaranteed under

in-use conditions for a period longer than the allowed 60 days after unpacking the drug product pre-stored even up to the end of shelf life.

*Registered trademark of AstraZeneca group of companies; for use within the USA as Pressair ${ }^{\circledR}$ and Genuair ${ }^{\mathrm{TM}}$ within all other licensed territories.

\section{P292 PILOT STUDY TO ASSESS BRONCHODILATOR RESPONSE DURING AN ACUTE EXACERBATION OF COPD USING A VIBRATING MESH NEBULISER VERSUS JET NEBULISER FOR BRONCHODILATOR DELIVERY}

B Cushen, A Alsaid, A Abdulkareem, RW Costello. RCSI Beaumont Hospital, Dublin, Ireland

\subsection{6/thoraxjnl-2016-209333.435}

Introduction Recovery from COPD exacerbation is associated with increases in respirable lung volume. Accelerating these changes through improved bronchodilator delivery could hasten recovery.

Hypothesis Vibrating mesh nebuliser (Aerogen ${ }^{\circledR}$ Ultra) results in greater change in lung physiology compared to standard small volume jet nebuliser.

Methods Patients with an exacerbation of COPD were randomised to receive combined salbutamol $2.5 \mathrm{mg}$ /ipratropium bromide $0.5 \mathrm{mg}$ via vibrating mesh (Active group) or standard hospital jet nebuliser (Control) on one occasion between day 2-7 of hospitalisation. Spirometry, body plethysmography and impulse oscillometry were performed pre-bronchodilator and at 1 hour post. Borg breathlessness score was measured.

Results Thirty-one patients have been recruited to date, 16 to the active group and 15 control group. Mean FEV 1 was $48 \pm 18 \%$ predicted. Baseline demographics were comparable between groups. Both groups had significant improvements in $\mathrm{FEV}_{1}$ and Inspiratory Capacity post-bronchodilator, with greater increases in FVC in the active group $(0.40 \pm 0.39 \mathrm{~L}$ vs $0.19 \pm 0.19 \mathrm{~L}$, $\mathrm{p}=0.06)$. Significant changes in operating lung volumes and airway impedance were seen in both groups. There was no significant difference in Borg score.

Conclusion Bronchodilator administration, during a COPD exacerbation, results in significant improvements in spirometry, lung volume and airway impedance. Drug delivery by vibrating mesh nebuliser results in greater absolute increases in FVC. Further studies will assess whether this translates into accelerated exacerbation recovery.
DRUG DELIVERY PERFORMANCE OF BUDESONIDE (BD), GLYCOPYRRONIUM (GP) AND FORMOTEROL (FF) TRIPLE COMBINATION (BGF) CO-SUSPENSIONTM DELIVERY TECHNOLOGY MDIS

${ }^{1} \mathrm{~V}$ Joshi, ${ }^{2} \mathrm{P}$ Mack, ${ }^{2} \mathrm{~A}$ Archbell, ${ }^{2} \mathrm{G} L \mathrm{Li},{ }^{2} \mathrm{M}$ Arent, ${ }^{2} \mathrm{~K}$ Vang, ${ }^{2} \mathrm{~S}$ Ivatury, ${ }^{2} \mathrm{R}$ Schultz, ${ }^{2}$ D Lechuga-Ballesteros, ${ }^{2} \mathrm{~S}$ Dwivedi, ${ }^{2} \mathrm{M}$ Riebe. ${ }^{1}$ Pearl Therapeutics Inc., Redwood City, USA; ${ }^{2}$ Pearl Therapeutics Inc., Durham, USA

\subsection{6/thoraxjnl-2016-209333.436}

Introduction To assure consistency of clinical outcomes, orally inhaled products must have consistent in vitro delivered dose and aerosol properties. Achieving this consistency has been challenging with MDIs, particularly those that combine multiple drugs. Co-Suspension ${ }^{\mathrm{TM}}$ delivery technology has been developed for in vitro drug-drug interaction-free delivery of multiple drugs from fixed-dose MDI combinations. This versatile technology suspends the micronised drugs with spray-dried phospholipid porous particles in hydrofluoroalkane propellant. The objective of this study was to determine whether BGF MDI, the triple Co-Suspension delivery technology formulation of $\mathrm{BD} / \mathrm{GP} / \mathrm{FF}$, displays in vitro drug delivery comparable to its constituent single and dual drug formulations.

Methods Single, dual and triple therapy MDIs of BD, GP and FF were prepared by suspending each drug's microcrystals with phospholipid porous particles in HFA propellant. In vitro drug delivery was assessed by comparing delivered dose uniformity and aerodynamic particle size distribution.

Results BD, GP and FF formed stable suspensions in the presence of phospholipid porous particles, despite differences in drug physicochemical properties and doses. A consistent and comparable delivered dose and aerodynamic particle size distribution was observed whether emitted from a single, dual or triple therapy MDI.

Conclusion The single, dual and triple drug MDI formulations demonstrated comparable aerosol characteristics which should enable patients to transition across the continuum of these MDI therapies without in vitro drug-drug interaction impacting drug delivery and clinical outcomes.

\section{P294 BENEFITS OF TIOTROPIUM/OLODATEROL OVER TIOTROPIUM AT DELAYING CLINICALLY SIGNIFICANT EVENTS IN PATIENTS WITH COPD CLASSIFIED AS GOLD B}

${ }^{1} \mathrm{R}$ Buhl, ${ }^{2} \mathrm{~L}$ McGarvey, ${ }^{1} \mathrm{~S}$ Korn, ${ }^{3} \mathrm{GT}$ Ferguson, ${ }^{4} \mathrm{~L}$ Grönke, ${ }^{4} \mathrm{C}$ Hallmann, ${ }^{4} \mathrm{~F}$ Voß, ${ }^{5} \mathrm{KF}$ Rabe, ${ }^{6} \mathrm{~F}$ Maltais. ${ }^{1}$ Pulmonary Department, Mainz University Hospital, Mainz, Germany; ${ }^{2}$ Centre for Infection and Immunity, School of Medicine, Dentistry and Biomedical Sciences, Queen's University Belfast, Belfast, UK; ${ }^{3}$ Pulmonary Research Institute of Southeast Michigan, Farmington Hills, Michigan, USA; ${ }^{4}$ Boehringer Ingelheim Pharma GmbH and Co. $K G$, Ingelheim, Germany; ${ }^{5}$ LungenClinic Grosshansdorf, Grosshansdorf, Germany; ${ }^{6}$ Centre de Recherche, Institut Universitaire de Cardiologie et de Pneumologie de Québec, Québec, Canada

\subsection{6/thoraxjn--2016-209333.437}

Rationale The once-daily combination of tiotropium (T), a longacting muscarinic antagonist, and olodaterol $(\mathrm{O})$, a long-acting $\beta_{2}$-agonist, has demonstrated efficacy and safety in COPD. Two large clinical studies (TONADO $1+2$ ) have also demonstrated the benefits of $\mathrm{T} / \mathrm{O}$ compared to the monocomponents in patients with moderate to very severe COPD. This post hoc analysis investigated whether $\mathrm{T} / \mathrm{O}$ is more effective than $\mathrm{T}$ at delaying 


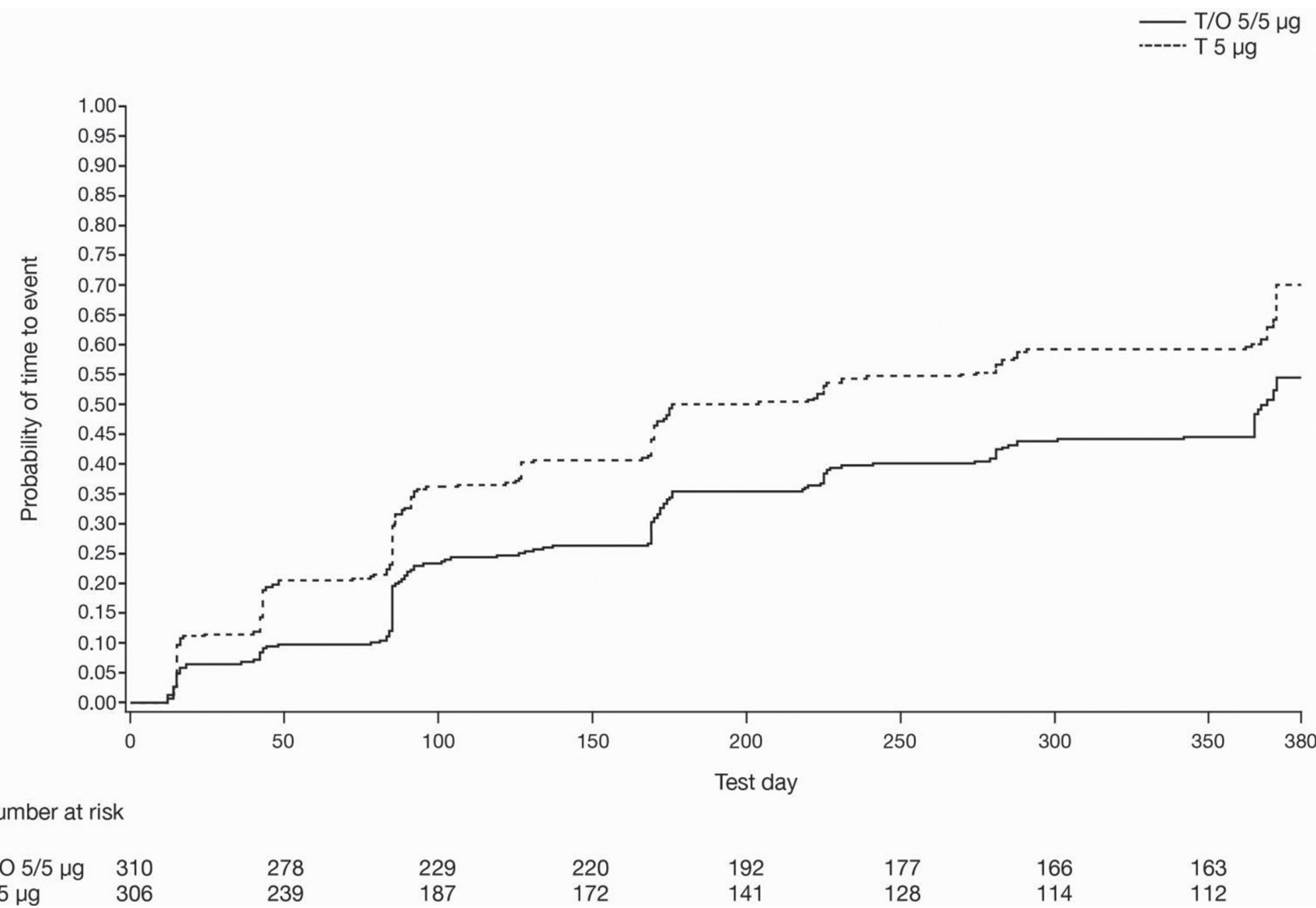

Abstract P294 Figure 1 Kaplan-Meier estimates of time to clinically significant event (decline from baseline $\mathrm{FEV}_{1}$ of $\geq 100 \mathrm{~mL}$; increase from baseline of $\geq 4$ units SGRQ total score; severe exacerbation; death) in patients with GOLD stage B COPD

clinically significant events in patients with GOLD stage B COPD.

Methods A total of 5162 patients were randomised to $\mathrm{O} 5 \mu \mathrm{g}$, $\mathrm{T} 2.5 \mu \mathrm{g}, \mathrm{T} 5 \mu \mathrm{g}, \mathrm{T} / \mathrm{O} 2.5 / 5 \mu \mathrm{g}$ or $\mathrm{T} / \mathrm{O} 5 / 5 \mu \mathrm{g}$ (delivered via Respimat inhaler) in two 52-week, parallel-group, double-blind studies (NCT01431274; NCT01431287). In this post hoc analysis of the combined TONADO ${ }^{\circledast}$ data, clinical deterioration was defined according to a composite end point: time to first decrease in trough forced expiratory volume in 1 second $\left(\mathrm{FEV}_{1}\right)$ from baseline of $\geq 100 \mathrm{~mL}$; increase in St George's Respiratory Questionnaire (SGRQ) total score from baseline of $\geq 4$ units; severe (hospitalised) exacerbation; or death. Only patients classified as GOLD stage B were included. Data are presented for comparisons of the licensed doses of T $5 \mu \mathrm{g}$ and T/O $5 / 5 \mu \mathrm{g}$.

Results 306 and 310 patients were included in this analysis in the $\mathrm{T} 5 \mu \mathrm{g}$ and $\mathrm{T} / \mathrm{O} 5 / 5 \mu \mathrm{g}$ treatment groups, respectively. Time to clinical deterioration was significantly longer with $\mathrm{T} / \mathrm{O} 5 / 5 \mu \mathrm{g}$ than T $5 \mu \mathrm{g}$ (25th percentile 128 versus 85 days; HR 0.650; 95\% CI: 0.524, 0.805; p < 0.0001) (Figure). Times to trough $\mathrm{FEV}_{1}$ decline and SGRQ increase were significantly longer with $\mathrm{T} / \mathrm{O} 5 / 5 \mu \mathrm{g}$ than T $5 \mu \mathrm{g}$ (226 versus 91 days and 369 versus 175 days, respectively). $25^{\text {th }}$ percentiles for time to severe exacerbation and time to death were not estimable due to low event rates. Conclusions In the TONADO ${ }^{\circledast}$ studies, T/O increased time to clinical deterioration compared to $\mathrm{T}$ alone in patients with GOLD stage $B$ disease. This suggests that, in this patient population, $\mathrm{T} / \mathrm{O}$ is more effective than $\mathrm{T}$ in preventing these significant events. Further studies are warranted to prospectively study this effect.

Funding Boehringer Ingelheim.

Please refer to page A272 for declarations of interest in relation to abstract P294.

\section{P295 EFFICACY AND SAFETY OF TIOTROPIUM/OLODATEROL IN PATIENTS WITH COPD BY ATS CATEGORY}

${ }^{1} \mathrm{~F}$ Maltais, ${ }^{2} \mathrm{E}$ Pizzichini, ${ }^{3} \mathrm{~L}$ Grönke, ${ }^{3} \mathrm{~F}$ Voß, ${ }^{4} \mathrm{E}$ Derom. ${ }^{1}$ Département de Médecine, Centre de Recherche, Institut Universitaire de Cardiologie et de Pneumologie de Québec, Québec, Canada; ${ }^{2}$ Department of Pulmonology, NUPAIVA (Asthma Research Centre), Universidade Federal de Santa Catarina, Santa Catarina, Brazil; ${ }^{3}$ Boehringer Ingelheim Pharma GmbH and Co. KG, Ingelheim, Germany; ${ }^{4}$ Department of Respiratory Medicine, Ghent University Hospital, Ghent, Belgium

\subsection{6/thoraxjnl-2016-209333.438}

Rationale The once-daily combination of tiotropium (T), a longacting muscarinic antagonist, and olodaterol $(\mathrm{O})$, a long-acting $\beta_{2}$-agonist, has demonstrated efficacy and safety in chronic obstructive pulmonary disease (COPD). ${ }^{1}$ Recently, it has been demonstrated that patients with milder disease (GOLD 2) have better bronchodilator responses compared to those with more severe disease. This post hoc analysis investigated whether the response to $\mathrm{T} / \mathrm{O}$ and to $\mathrm{T}$ alone is influenced by forced expiratory volume in 1 second $\left(\mathrm{FEV}_{1}\right)$ American Thoracic Society (ATS) category (mild, moderate or severe). 